\title{
CHOOSING THE RIGHT PUBLIC TRANSPORT SOLUTION BASED ON PERFORMANCE OF COMPONENTS
}

\author{
Eric BRUUN ${ }^{1 *}$, Duncan ALLEN ${ }^{2}$, Moshe GIVONI ${ }^{3}$ \\ ${ }^{1}$ Kyyti Group Ltd, Helsinki, Finland \\ ${ }^{2}$ IBI Group, Boston, Massachusetts, United States \\ ${ }^{3}$ Transport Research Unit, Department of Geography and the Human Environment, Tel Aviv University, Israel
}

Received 11 November 2016; revised 25 May 2017; accepted 7 July 2017

\begin{abstract}
Planners often focus on a specific mode too early in the design and selection process, especially on the choice between bus and rail technology. It may be that available Right of Way (RoW), alignment characteristics and other design features are more important. In this paper, we first identify the principal components central to performance of a particular role common to all major Public Transport (PT) investments. The primary aim is to offer a more mode-neutral alternative selection process that benefits from ex-post cost and performance information about a substantial number of actual PT systems broken down into these components to the extent that is possible. Less quantitative components and features, such as passenger experience, scalability, and implementability are then discussed for their role in increasing or diminishing the attractiveness of alternative candidate component packages in the desired range of the quantitative criteria. The results show that investment costs increase with the degree of separation of RoW, regardless of rail or bus technology, with rail having an additive "technology premium". Higher Average Operating Speed (AOS) reduces investment in vehicles and the Operating and Maintenance (O\&M) cost, regardless of technology. At low/moderate passenger traffic densities, Semirapid Bus modes have lower O\&M costs than Semirapid Rail. At the highest densities, Rapid Rail and Regional Rail modes exhibit clear economies of scale. For mixed street running, rail-related components cause a far more expensive total investment on per unit of Productive Capacity (PC) basis. As the required PC increases, rail modes become consistently less expensive. The main conclusion is that in order to improve value-for-money of PT it is critical to develop innovative component technologies and construction techniques, which are not necessarily rail or bus specific.
\end{abstract}

Keywords: public transport, performance indicators, public transport costs, project evaluation, right of way costs, bus rapid transit, light rail transit, transport infrastructure.

\section{Introduction: fit for fashion or purpose?}

The vision for Public Transport (PT) projects at both the metropolitan and corridor levels is often prematurely focused on a particular "obvious" mode such as Bus Rapid Transit (BRT), Light Rail Transit (LRT). These two especially have stimulated futile and unproductive academic and practice debates (e.g. Stutsman 2002; Currie, Delbosc 2013; Mulley et al. 2014; Hensher, Mulley 2015; Hensher 2016). In addition, the debate can be fuelled by commercial and political interests making the choice of the suitable PT system a messy (Ney 2009) process.

In this context, the aim of this article is to promote a more mode-neutral approach to the selection of PT investment packages. It is designed to take advantage of empirical findings about performance of existing transport systems to help untangle what is actually attributable to an inherent mode-specific feature and what is attributable to the specifics of a site. In this way, it becomes possible to find alternatives that suit a project's design goals and objectives to the maximum extent that is practical and realistic, instead of prematurely choosing a specific modal solution that constrains the problem to fit the solution, instead of vice versa. The ex-post data for PT systems presented and discussed here are limited to urban and regional PT, but the methodology discussed here would also be applicable to longer distance transport.

The paper progresses through five sections. In Section 1 the currently imprecise labelling of modes is discussed. A sampling of actual systems illustrates how a technical term like BRT can be applied to PT systems, which are very different in characteristics and performance. A revised

*Corresponding author. E-mail: eric.bruun@gmx.com 
terminology of PT systems is then suggested in order to support the analysis and discussion that follows. Section 2 then sketches out the principal components to consider when choosing a PT system, followed by Section 3 where the data sources and methodology used for the analysis are presented. In Section 4 the empirical results and analysis are presented; a summary of the main findings and some observations close the paper in the last section.

\section{PT systems terminology in the professional literature}

\subsection{History and current practice of labelling of modes}

Several archetypes of PT are widely recognized. Although useful for the debate in professional, policy and academic circles, the categorization of PT systems under a particular type is likely to be counterproductive for the discussion and choice of such a system for a particular city. This is most apparent in the current PT debate, which is bogged down by the use of the terms LRT and BRT.

Conceived of in the 1970s as a lower-cost form of Rail Rapid Transit (RRT), the distinctive feature of LRT was electric vehicles using an Overhead Contact System (OCS) and therefore able to cross intersections at grade and operate primarily in lateral separated lanes $\left(\mathrm{RoW} \mathrm{B}^{1}\right)$ but also in mixed traffic out of necessity (RoW C) to contain costs. The definition, however, has never really been that sharp. Buffalo, USA branded its predominantly underground system as "light rail rapid transit" (LRRT), and in Calgary, Canada the recently opened West Line, regarded as LRT, is almost indistinguishable from RRT except for a few atgrade crossings. At the other end of the range of physical attributes, elements of North American streetcar systems that survived the 1960s have also been considered LRT. At the Transportation Research Board (TRB)'s series of National Light Rail Conferences in the US, John W. Schumann ${ }^{2}$ has been using an Average Operating Speed (AOS) of $24 \mathrm{~km} / \mathrm{h}$ to distinguish between a faster "Class I" and slower "Class II" of LRT systems. In European parlance, the word "tramway" has similarly acquired variant usages. Most systems recognized or described in the literature as LRT would fall into this category.

The origins of BRT are similar: a notion of achieving the higher levels of performance popularly associated with LRT with less capital-intensive bus technology. The term may not have been aptly coined, because it was formed with LRT as a basis, and as noted above not all LRT is "rapid". Moreover, the middle letter of the LRT acronym is "rail". Many of the first set of BRT projects in the US did not meet the speed standard of Schumann's Class I, although the most recent addition at the time of writing, Hartford's CTfastrak (Connecticut, USA) exceeds it easily.

\footnotetext{
${ }^{1}$ See Table 2, Note 1 for definition.

${ }^{2}$ In each conference's proceedings, John W. Schumann has published a paper entitled "Status of North American LRT Systems".
}

Over time, the term "BRT" became associated with a set of advanced attributes that a bus service might have, leading recently to the development of the ITDP's notion of rating BRT systems based primarily on the number of such attributes present rather than the extent to which they achieve the levels of speed and reliability characteristic of RRT systems operating at or below capacity. Similarly, in the US the Federal Transit Administration (US FTA), in collaboration with the industry, has defined the key characteristics of BRT, with speed directly referred to under the service category ${ }^{3}$ (Jarzab et al. 2002). The emergence of the terms "BRT lite" in North America and 'bus à haut niveau de service' (Finn et al. 2011) in France, point to a need to make some distinctions among bus-based systems.

\subsection{A sampling of PT systems of different roles and performance bearing the same popular name}

Table 1 shows how different in characteristics systems using the same basic vehicle technology can be. It provides a sense of the range of distinctly different operations with which the term "BRT" has been associated in North America (the methodology, data and data sources used to produce Table 1 are explained in Section 3). The principal attributes these systems have in common are the use of "BRT"-styled vehicles and a visibly richer set of passenger amenities than typical local bus stops and vehicles, not simply to improve passenger experience but also to promote a local "brand" or image. The range across this table shows significant differences in average speed, frequency, and stop spacing, the main attributes which differentiate among PT categories. Table 2 is thus presented to give an alternative set of labels considering these attributes.

The nine systems presented in Table 1 are sorted in descending order of construction cost (with the exception of the first two) and only the first system is considered, from our perspective, to be a genuine Rapid Bus system. According to Table 2, all of the remaining would be either Semirapid Bus or Local Bus.

Frequency of service is generally much higher for BRT services than for the former services they replaced. This is not necessarily a technical constraint on Pre-BRT local services, for which several routes may stop along the same road to give a high average frequency. Rather it reflects a service reconfiguration into a trunk-feeder system. Such services have a very high traffic density along the trunk line, which enables the use of both larger vehicles and more frequent service. For example despite its high speed and longer stop spacing, thus meriting the local branding as an "enhanced bus", the KCATA State Avenue service is functionally a Local Bus. It has a very low frequency of only 31 trips per day per direction and a much lower traffic density than the five others for which statistics are available (three of the services are very new).

Capital costs for enhanced Local Bus services (that

\footnotetext{
3 "Service: BRT systems should provide fast, frequent, and reliable service, with stops spacing of 1 mile or more" (Jarzab et al. 2002).
} 
Table 1. Terminology vs. characteristics of some different bus systems

\begin{tabular}{|c|c|c|c|c|c|c|c|c|c|}
\hline Project & $\begin{array}{l}\text { Hartford, } \\
\text { Connecticut } \\
\text { CT fastrak }\end{array}$ & $\begin{array}{l}\text { Cleveland, } \\
\text { Ohio } \\
\text { HealthLine }\end{array}$ & $\begin{array}{c}\text { Eugene, } \\
\text { Oregon } \\
\text { EmX }\end{array}$ & $\begin{array}{l}\text { YRT VIVA } \\
\text { Phase I } \\
\text { (system) }\end{array}$ & $\begin{array}{c}\text { KCATA } \\
\text { Troost } \\
\text { MAX }\end{array}$ & $\begin{array}{l}\text { CDTA } \\
\text { BusPlus } \\
\text { (red) }\end{array}$ & $\begin{array}{l}\text { LACMTA } \\
\text { Metro } \\
\text { Rapid } 720\end{array}$ & $\begin{array}{l}\text { Providence, } \\
\text { Rhode } \\
\text { Island } \\
\text { R-Line }\end{array}$ & $\begin{array}{l}\text { KCATA } \\
\text { State } \\
\text { Avenue }\end{array}$ \\
\hline $\begin{array}{l}\text { Initial operating } \\
\text { year }\end{array}$ & 2015 & 2008 & 2007 & 2005 & 2011 & 2011 & 2000 & 2014 & 2014 \\
\hline Local Branding & \multicolumn{6}{|c|}{ BRT } & \multicolumn{2}{|c|}{ Rapid bus } & $\begin{array}{c}\text { Enhanced } \\
\text { bus }\end{array}$ \\
\hline $\begin{array}{l}\text { Category for this } \\
\text { paper }\end{array}$ & Rapid Bus & \multicolumn{6}{|c|}{ Semirapid Bus } & \multicolumn{2}{|c|}{ Local Bus } \\
\hline Length $[\mathrm{km}]$ & 15.1 & 11.4 & 11.6 & 90 & 21.5 & 26.6 & 41.4 & 12.1 & 25 \\
\hline $\begin{array}{l}\text { Predominant } \\
\text { RoW type }\end{array}$ & A & B & B & $\mathrm{C}$ & $\mathrm{C}$ & $\mathrm{C}$ & $\mathrm{C}$ & $\mathrm{C}$ & $\mathrm{C}$ \\
\hline Stops & 11 & 30 & 23 & 62 & 40 & 14 & 36 & 28 & 23 \\
\hline $\begin{array}{l}\text { Average stop } \\
\text { spacing }[\mathrm{m}]\end{array}$ & 1510 & 394 & 527 & 1450 & 551 & 756 & 1183 & 448 & 1136 \\
\hline $\begin{array}{l}\text { Peak running time } \\
\text { [min] }\end{array}$ & 24 & 38 & 43 & N/A & 52 & 28 & 126 & 51 & 56 \\
\hline $\begin{array}{l}\text { Average peak } \\
\text { operating } \\
\text { speed }[\mathrm{km} / \mathrm{h}]\end{array}$ & 37.7 & 18 & 16,4 & 20.9 & 24.8 & 21.1 & 19.7 & 14.2 & 26.7 \\
\hline $\begin{array}{l}\text { Trips per direction } \\
\text { per weekday }\end{array}$ & $\begin{array}{c}164 \\
\text { (all stops) }\end{array}$ & 131 & 89 & $\begin{array}{l}85 \ldots 135 \\
\text { (by route) }\end{array}$ & 90 & 116 & 150 & 102 & 31 \\
\hline $\begin{array}{l}\text { Traffic density } \\
\text { [passenger } \mathrm{km} \text { per } \\
\text { year/route } \cdot \mathrm{km} \text { ] }\end{array}$ & N/A & 1727691 & 1420000 & 875000 & N/A & 967000 & 2130000 & N/A & 372000 \\
\hline $\begin{array}{l}\text { Annual boardings } \\
\text { per route } \mathrm{km}\end{array}$ & N/A & 405000 & 276000 & 104000 & 121000 & 152000 & 415000 & 265000 & 21000 \\
\hline $\begin{array}{l}\text { Infrastructure } \\
\text { cost per route km } \\
(\text { millions } \$ 2012)\end{array}$ & $\$ 35.7$ & $\$ 36.7$ & $\$ 5.7$ & $\$ 2.2$ & $\$ 1.2$ & $\$ 0.7$ & $\$ 0.2$ & $\$ 0.2$ & $\$ 0.4$ \\
\hline
\end{tabular}

Notes:

1. Italics represent estimates by IBI Group, primarily from transit system websites;

2. Index: KCATA - Kansas City Area Transit Authority; YRT - York Regional Transit; CDTA - Capital District Transit Authority

(Albany, New York); LACMTA - Los Angeles County Metropolitan Transportation Authority;

3. All of these are in the USA, except for YRT Viva, which is in York, Ontario, Canada.

might be termed "BRT lite") and even some Semirapid Bus services, can be close to zero when stops are not much more than a signpost and existing amenities are used. The LACMTA MetroRapid 720 and YRT VIVA are essentially express services that overlay a Local Bus but with fewer stops. Costs climb when islands are built for stops, new shelters are provided, terminals are enhanced, and so on. The Cleveland Health Line has RoW B for most of its length, has preferential traffic signal control and otherwise very similar to new Semirapid Rail systems. The Hartford CTfastrak has RoW A.

The bottom line of the above comparison is that the different use made of the technology (in this case bus), is what differentiates among the PT systems described. The decision on the service attributes central to route performance, especially the RoW, the number and spacing of stops, and the cruising speed between stations, is the determining factor of the system, as opposed to the type of bus employed and its branding. This is not to say that 'branding' of bus services is not important, only that it is not so important for choosing the right bus system for a particular case. Similar arguments and examples could have been produced for so-called LRT systems.

Instead of the LRT vs. BRT, the terminology used herein is primarily based on the role or function within a PT network, which in turn implies some performance requirements especially with respect to: station-spacing and the type of infrastructure used (especially the RoW see Section 4). Accordingly, the analyses below are based on categories of PT that include: Local, Local with Express Segments, Semirapid, Rapid, Regional, and Rapid/ Regional Hybrid, the main characteristics of which are summarized in Table 2. Figure 1 shows some examples of key characteristics like RoW and stations. 
Table 2. The prevalent characteristics of PT categories

\begin{tabular}{|l|l|l|l|l|}
\hline PT category & Typical station or stop spacing & \multicolumn{1}{|c|}{ RoW $^{1}$} & \multicolumn{1}{|c|}{ Service Frequency } & \multicolumn{1}{|c|}{ Bus/Rail Vehicles } \\
\hline Local & $\begin{array}{l}\text { Between } 100 \mathrm{~m} \text { and } 400 \mathrm{~m}, \\
\text { sometimes on demand }\end{array}$ & RoW C & $\begin{array}{l}1 \ldots 20 \text { per hour, varying } \\
\text { by time of day }\end{array}$ & $\begin{array}{l}\text { Local Bus/Local Rail } \\
\text { (streetcar or tram) }\end{array}$ \\
\hline Local/Express & $\begin{array}{l}\text { Like local but with few or no } \\
\text { stops in express zones }\end{array}$ & $\begin{array}{l}\text { RoW C local, } \\
\text { RoW A or RoW C } \\
\text { in express zones }\end{array}$ & $\begin{array}{l}\text { Like local, but may be } \\
\text { offered only in peaks as } \\
\text { a supplement to local }\end{array}$ & $\begin{array}{l}\text { Local Bus/Local Rail } \\
\text { (streetcar or tram) }\end{array}$ \\
\hline Semirapid & Between $300 \mathrm{~m}$ and $1000 \mathrm{~m}$ & $\begin{array}{l}\text { Mostly RoW B, } \\
\text { some RoW A and } \\
\text { RoW C possible }\end{array}$ & $\begin{array}{l}4 \ldots 8 \text { per hour, } \\
\text { occasionally more }\end{array}$ & $\begin{array}{l}\text { Typically articulated stylized } \\
\text { bus/LRV } \text { or high-capacity } \\
\text { streetcar (tram) }\end{array}$ \\
\hline $\begin{array}{l}\text { Rapid } \\
\text { Regional } \\
\text { Hybrid }\end{array}$ & $\begin{array}{l}\text { Like Rapid in dense urban } \\
\text { areas, like Regional elsewhere }\end{array}$ & RoW A exclusive & $\begin{array}{l}4 \ldots 8 \text { per hour on } \\
\text { branches }\end{array}$ & $\begin{array}{l}\text { Typically articulated stylized } \\
\text { bus/Rapid Rail (metro) }\end{array}$ \\
\hline Regional & Greatylized bus)/Rapid Rail (metro) \\
\hline
\end{tabular}

Notes:

${ }^{1}$ Vuchic (2007) defines three basic types of Right of Way (RoW):

- RoW A: full separation from all other modes and no cross-traffic; the most expensive solution but also gives the best performance;

- RoW B: lateral separation such that the mode runs in a fully separated lane, but there is still at-grade cross traffic at intersections. It is intermediate in cost and performance;

- RoW C: Mixed traffic operation; usually requires little investment beyond the existing roadway and thus is the least expensive; it also usually means that PT will be slower than the private car;

${ }^{2}$ LRV - Light Rail Vehicle.

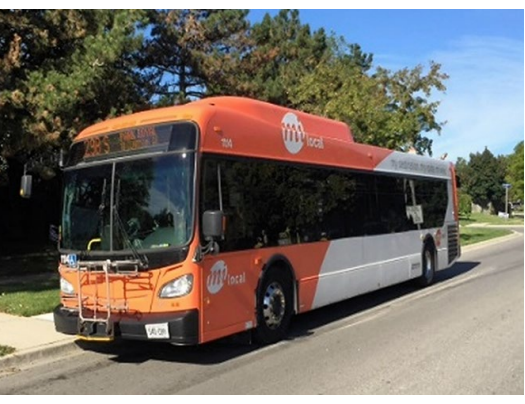

Local bus on a local street, RoW C, Mississauga, Canada

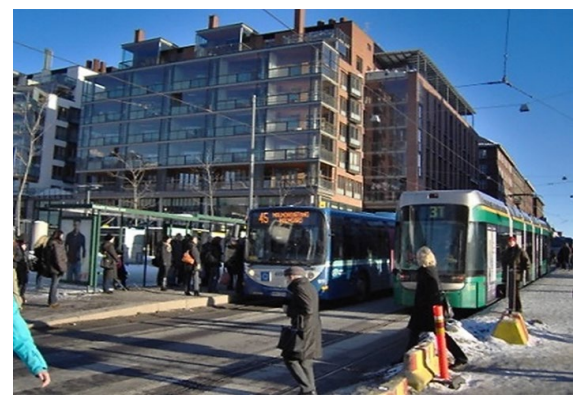

Minimal roadway work, local rail and local bus sharing RoW C, Helsinki

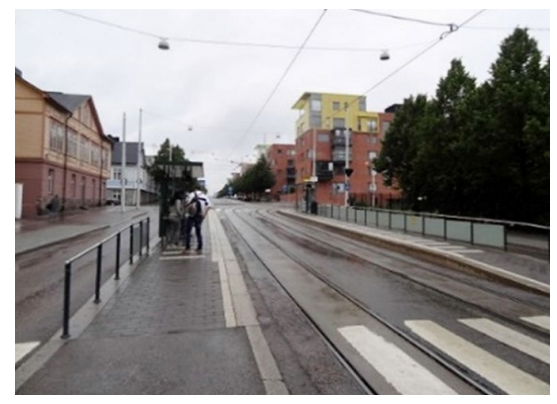

Low floor level boarding, RoW B localrail, Helsinki

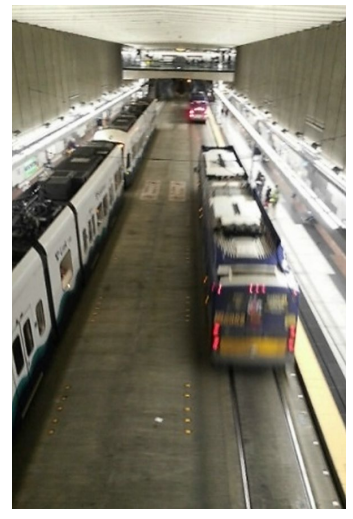

Tunnel fully separated RoW A local/express bus and semirapid rail, Seattle

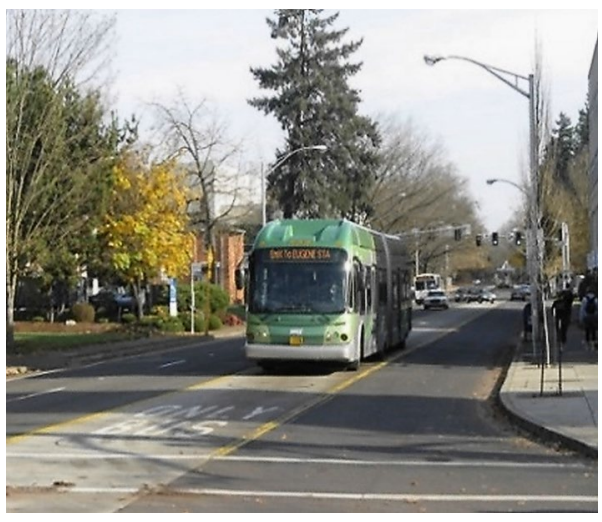

Minimal roadway work, semirapid bus, RoW B, Eugene

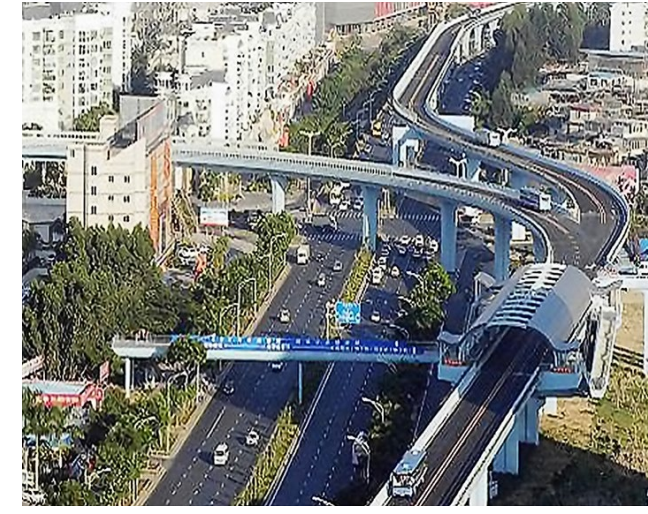

Elevated fully separated, RoW A busway, Xiamen

Figure 1. Different PT systems in different RoWs using Bus or Rail technologies 
We define in the next section the principal characteristics to consider when choosing a particular PT system for a particular city.

\section{The principal components for planning a PT system}

The principal components for planning a PT system can be simplified into three categories: Physical design features, economic and cost considerations, and the passenger experience elements. In turn, these can be further defined into some principal design features, as shown in Table 3.

Within the physical design component, the alignment aspect is of fundamental importance. This relates largely to the type of RoW envisaged, i.e. whether mixed traffic, lateral separation, or grade separation. The number of stations/stops number and their locations (and derived from these the station spacing), the station sizes and the need for curves and gradients are further central features of a given alignment. Vehicle design characteristics include their external size and internal space, dynamic performance such as cruising speed and acceleration and braking rates. For rail borne systems, this also means deciding on the basic size of the trainset (different multiple car configurations are possible). Capacity is another major element of the physical design component and it represents the ability to transport the planned number of travellers safely and reliably. This includes maintaining appropriate headways and managing appropriate boarding/alighting volumes at stations. Finally, the supporting infrastructure feature is the ancillary equipment needed to ensure that the system, together with the other features of the physical design, is operational. Supporting infrastructure can range from simple maintenance and storage facilities to tailor-made technology-specific depots, control centres and power supply systems.

Table 3. The principal components and design features for planning a PT system

\begin{tabular}{|l|l|}
\hline \multicolumn{1}{|c|}{ Component } & \multicolumn{1}{c|}{ Design features } \\
\hline $\begin{array}{l}\text { Physical design } \\
\text { features }\end{array}$ & $\begin{array}{l}\text { Alignment (to include consideration } \\
\text { of RoW, stations, infrastructure, etc.) }\end{array}$ \\
\cline { 2 - 2 } & Vehicles \\
\cline { 2 - 2 } & Capacity \\
\cline { 2 - 2 } & $\begin{array}{l}\text { Supporting infrastructure (signals and } \\
\text { controls, power supplies, depots, etc.) }\end{array}$ \\
\hline \multirow{2}{*}{$\begin{array}{l}\text { Economic/cost } \\
\text { considerations }\end{array}$} & Capital investments \\
\cline { 2 - 2 } & $\begin{array}{l}\text { Net Operating and Maintenance (O\&M) } \\
\text { cost }\end{array}$ \\
\cline { 2 - 2 } & Renewal/capacity expansion/extension cost \\
\hline $\begin{array}{l}\text { Passenger } \\
\text { experience } \\
\text { elements }\end{array}$ & Travel time \\
\cline { 2 - 2 } & Fare (price for the entire trip) \\
\cline { 2 - 2 } & Comfort/convenience \\
\hline Implementability & See Table 4 \\
\hline
\end{tabular}

As noted, capacity is important, but it is critical to distinguish this from throughput, the actual observed maximum number of passengers carried (see below). The Transit Capacity and Quality of Service: Manual (TCQSM) (TRB 2003) defines capacity in a specific fashion that makes for consistent comparisons between options and with peer locations, the importance of which is discussed and illustrated later in this paper. Many PT systems (like Transmilenio, in Bogotá, Colombia) operate over capacity by this definition. In many cases, more than one mode may be able to deliver the combination of speed and capacity that meets a city's needs. For this reason, the concept of Productive Capacity (PC), which combines the two as a product can be a good indicator of competitive alternatives ${ }^{4}$. For example, two alternatives having the same passenger capacity, but where one is much slower than the other are not competing alternatives for the same application, because the services they offer are not even close to comparable (Vuchic 2007). Much confusion stems from quotes about the passenger capacity of systems without taking into account other vital characteristics, speed in particular. Therefore, this paper uses the PC concept as one of its bases for comparison between PT systems.

The economic/cost component can be broken into three broad categories. The capital investments include hardware purchases, construction labour and materials, land acquisition and mitigations, and any debts and interest created by the procurement model used. The net O\&M costs are those needed to sustain daily operations, after user/beneficiary contributions are deducted. The costs of periodic renewal, including economic losses due to major disruptions to the functioning of a city, must also be considered in the economic/cost component. This is especially true when rapid growth in demand is expected; the ease and time required for service addition and for extension of the alignment can have a large bearing on the choice of system.

Passenger experience considerations should include both objective and subjective elements (indicators). Of central importance is travel time for the entire trip, doorto-door, including access, egress, and wait times, as well as (walking) transfer times when a network of services is considered. The perceived monetary price of the entire trip, the overall cost of getting from origin to destination using the PT system, is also central for determining the competitiveness of a proposed system. Finally, the comfort/convenience "package" that the user experiences, often referred to as the Quality of Service (QoS) (Hensher, Stanley 2003; Hensher et al. 2003; Dell'Olio et al. 2010, 2011; De Oña et al. 2016) must be suitable for the design context. Individuals are willing to trade some comfort/ convenience elements depending upon the travel time

\footnotetext{
4 The formula used in the analysis below is: Productive Capacity $(P C)=$ Passengers per Hour $\times$ Average Operating Speed (AOS) with Units of Passenger $\times$ Kilometers per Hour Squared.
} 
and price of the trip. Generally, comfort and convenience standards (e.g. crowding and on-board amenities) need to be higher for longer trips and as societies become more prosperous.

Although these are the principal components to consider when choosing a PT system, it is clear that other, largely practical, considerations also play an important role in the decision. These considerations are captured in the term "implementability" and relate to various barriers to implementing an otherwise preferred design alternative. Such barriers can include lack of financial resources, skilled labour force shortage, technological development risks, institutional barriers like lack of jurisdiction over the entire geographical area in question, etc. Particularly important to the Semirapid versus Rapid design alternative debate is the jurisdiction over the use and conversion/upgrade of existing roadways. A specific example is discussed in Section 4.

It is well established in the literature that policy making, certainly in the transport sector, is messy (Ney 2009) and "wicked" (Rittel, Webber 1973). Therefore, the design choices of a particular PT system will be influenced by criteria related to the above implementation barriers and by public and political acceptability issues. The known NIMBY ("not in my back yard") phenomenon, as well as political promises that have been made, can turn out to be the most powerful determinants of the choice of a PT system. Furthermore, the decision on a PT system could also turn on concerns about equity, funding restrictions, and other criteria. Finally, the prospects for a project often hinge on what other projects are simultaneously competing for funding, that is, on the opportunity costs. These implementability issues are summarized in Table 4.

\section{Data and computational methodology}

\subsection{Data typically versus used in this paper}

The analysis presented in this paper compares different PT systems (or parts of them) based on the main principal components and design features of PT as suggested in Table 3. The data presented and discussed are largely from North-American systems because these are more readily available. It might be that in the US and Canada evaluating and comparing projects is more widespread due to the reluctance to spend tax money, while in Europe it appears that the near mandatory outsourcing of operations means that private operators do not want to share their costs, regarding them as proprietary and affecting competition in future tendering and bidding. This should be a concern for policy and research purposes.

Reports and research papers in the public domain addressing investment and O\&M costs versus performance in the context of using ex-post experience from peers certainly exist. However, the contention of this paper is that they do not or cannot, due to lack of sufficient disaggregation by key component, provide the basis for a rigorous comparison of performance increase (such as reduced
Table 4. Attributes and political considerations used for setting weights on design goals

\begin{tabular}{|l|}
\hline Time frame: \\
- quick effects; \\
- long term network development; \\
- long term urban form. \\
\hline Equity: \\
- area coverage (multiple projects of lower standard versus \\
$\quad$ one); \\
- distribution of benefits versus costs; \\
- fairness in economic development benefits; \\
- service quality standard consistency. \\
\hline Risk assessment: \\
- cost overrun probability; \\
- legislation or legal challenge delay probability; \\
- construction delay probability; \\
- failure to perform as required probability: \\
- demand uncertainty; \\
- immature technology; \\
- lack of assumed cooperation. \\
\hline Aesthetics: \\
- beauty (appeal) versus cost; \\
- conformance with neighbourhood standards; \\
- noise mitigation; \\
- traffic impacts. \\
\hline Funding source obligations: \\
- matching funds may be mode dependent; \\
- landscape architecture, neighbourhood improvements, \\
etc. \\
\hline Opportunity costs: \\
- other potential projects in the region; \\
- potential loss of funds to other regions. \\
\end{tabular}

O\&M cost or higher operating speed) versus component cost increase. There may indeed be such databases in the private domain, retained by consultants for competitive advantage.

\subsection{Data sources}

A wide range of data sources were used to collect the data presented in the next section. Most of the data for PT route O\&M costs, speeds, and other operating characteristics were obtained from the US Federal Transit Administration's National Transit Database for 2012 (FTA 2013) or the Canadian Urban Transit Association's Canadian Transit Fact Book: 2012 Operating Data (CUTA 2013). Significant secondary sources included CERTU's 2007-2012 statistical abstract "transports collectifs urbains" (CEREMA 2014) and Currie, Delbosc's (2014) survey paper Assessing Bus Rapid Transit System Performance in Australasia. Other data were obtained from project websites.

The above sources also provided information on capital costs. These were obtained from secondary sources and compendia and were fact-checked against project websites, with care taken to exclude vehicle costs from total project costs; real estate costs were included. For North American Semirapid Bus systems, US FTA and Transport Canada project evaluation reports were consulted. Conversions to 
year 2012 USD (\$) were made by converting currencies as of the mid-year of construction, and then bringing them to 2012 \$ using the US Consumer Price Index. The costs therefore are representative of the collective experience of North America, Europe, and Australasia.

The selection of systems to include in the analysis was mainly based on data availability and is not meant to be statistically representative. Indeed, only a few samples exist for some of the modal subcategories. The intent was to illustrate and present the range in the attributes of these systems, using the categories defined in Table 3 , and with respect to cost, capacity, speed and other key variables. The data on which the Figures 2-6 rely on are presented in Appendix. Overall 117 PT networks are included in the analysis presented below (over $90 \%$ from North America) and 253 PT routes (70\% from North America, 23\% from Europe and the remainder from Asia, Australasia, South America and Africa).

\subsection{Capacity computation and actual throughputs}

Route capacities were estimated by methods consistent with Transit Cooperative Research Program (TCRP) Report 100, the aforementioned TCQSM (TRB 2003). Vehicle data were gathered from project websites and secondary sources, and vehicle capacities were estimated at a uniform four standees per square meter of standing area, the design load standard for most of Europe and North America. Data published in the TCQSM's Table 5-28 (TRB 2003) were included. Capacities reflect what the facility can carry, rather than the capacity of the current scheduled service and fleet assigned to it. The most common limiting factors for the capacity were platform or berthing arrangements and bus sizes or train length. The capacityreducing effects of traffic signals were estimated based on TCQSM Equations (4-6) (TRB 2003), with average traffic signal spacings estimated from project data or Google Earth imagery where available.

The route throughputs actually-delivered, both in terms of transport units and passengers were identified from secondary sources including lists and compendia of corridors available on the Internet, and were then scrutinized by consulting individual project and transit agency websites. It should be noted that multi-project compendia were found to contain cases where throughput may have been expressed as a combination of both directions of travel, to be for a 'peak' of indeterminate length instead of the more standard one hour, or even where total boarding may have been reported rather than throughput at a particular location. Throughputs were only tabulated when it could be ascertained that the value was very likely to represent a one-hour count of persons carried across the maximum load section (the busiest part of the network or route) in the peak direction.

\section{Unpacking the trade-offs between the principal components of a PT system - an empirical analysis}

Below, and with reference to Table 3, an ex-post comparison between the main characteristics of different PT systems is presented.

\subsection{Cost, capacity and RoW}

The principal alignment characteristics used for the comparison between systems range from minimal roadway work up to fully separated underground RoW, for both the bus and rail technologies. Figure 2 shows a range of observed capital costs per $\mathrm{km}$ of route in various settings, excluding vehicles, for increasingly involved construction efforts corresponding to these types of situations. This includes both the RoW itself (real estate), running surfaces, structures, and all supporting infrastructure depending upon propulsion and control systems, and stations of the lengths required. The RoW or setting is what makes the biggest difference in cost, not the vehicle technology (mode). The costs for both rail and bus-based technologies climb in tandem and the range of observed cost varies much more as construction moves above or underground. Differences in real estate costs also contribute to the wide range; land prices vary considerably among metropolitan areas, and within a metropolitan area unit, land costs can vary by an order of magnitude and depend largely on location. The specific local characteristics of a city are what in the end determine the cost for a certain alignment using a certain RoW type. On average, the infrastructure costs of bus-based PT systems appear to be lower when compared with rail based systems for similar settings. However, the width of the ranges does not mean that this can be taken for granted. It is more appropriate to think of rail as having a "technology premium" that does not rise nearly in proportion to overall cost, so that at the fully-separated end of the spectrum, this "premium" is a rather small fraction of system cost (which should be verified to indeed be present under local circumstances).

The economic/cost component can be broken into three broad categories. The capital investments include hardware purchases, construction labour and materials, land acquisition and mitigations, and any debts and interest created by the procurement model used. The net O\&M costs are those needed to sustain daily operations, after user/beneficiary contributions are deducted. The costs of periodic renewal, including economic losses due to major disruptions to the functioning of a city, must also be considered in the economic/cost component. This is especially true when rapid growth in demand is expected; the ease and time required for service addition and extension of the alignment can have a large bearing on the choice of system. 
As was discussed in Section 3, the cost per unit of PC might be a good indicator of the value for money that each RoW provides because it ensures that the combinations of speed and capacity provided are comparable. To generate Figure 3, the specific value used for passengers per hour is the throughput as defined by the TQSCM multiplied by the AOS, the speed experienced by passengers. For a graph showing PC values for a larger set of systems around the world see Vuchic (2007).

The left side of Figure 3 shows that a basic mobility service on existing streets in mixed traffic will cost less with bus technology; the "technology premium" for rail can be larger than all other project costs. The relationship changes for the other, more involved settings and

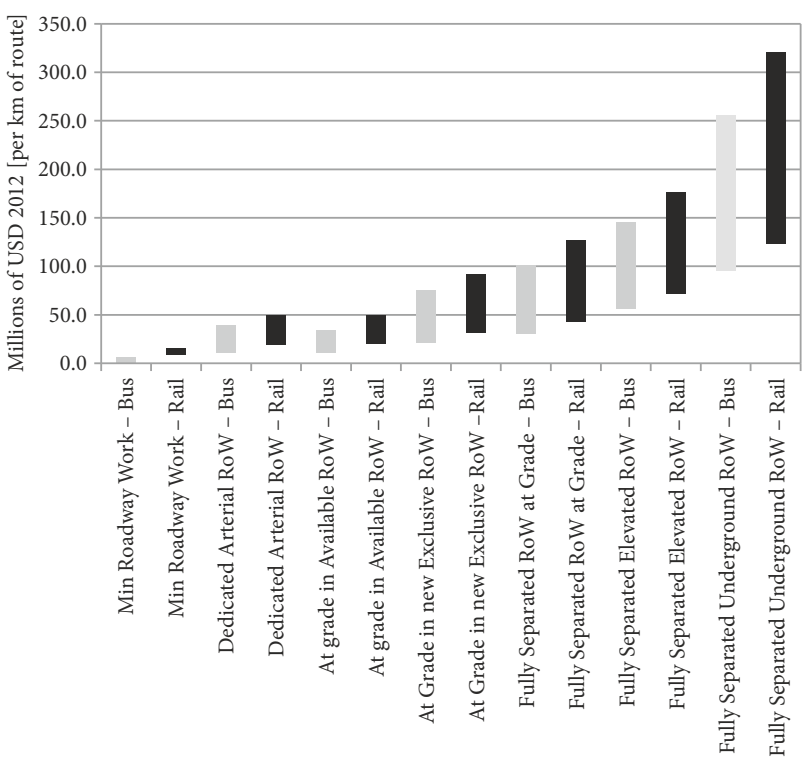

Figure 2. Capital cost of PT in different settings

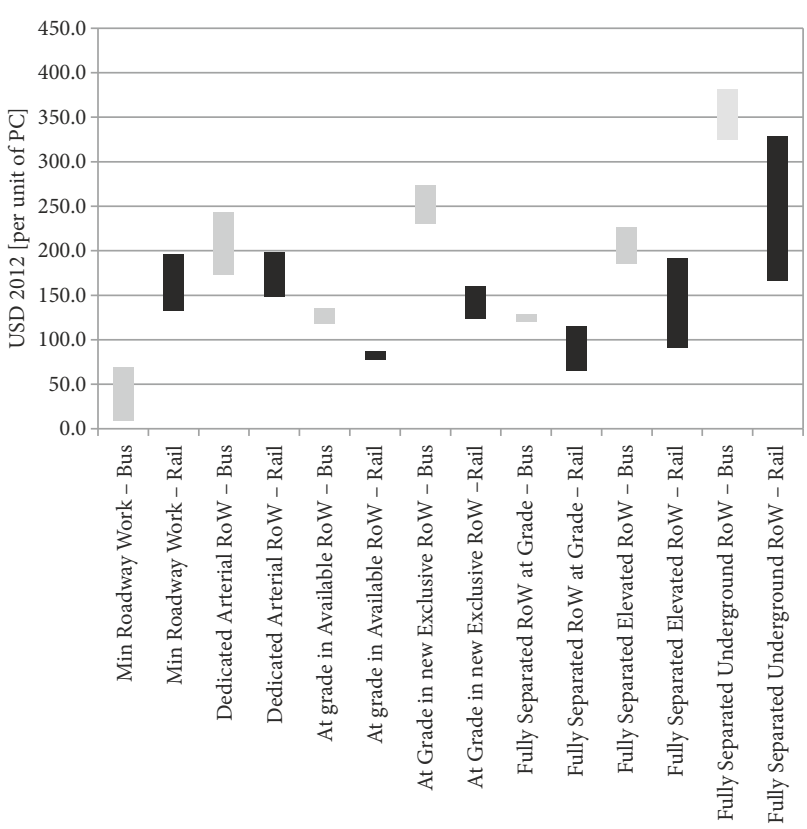

Figure 3. PC components of PT in different settings the rail 'technology premium' becomes lower relative to other project costs. For the case of a dedicated Arterial RoW, the bus and rail system ranges very much overlap, but for higher-performance RoW configurations the overlap between the bus and rail technology choice is small or non-existent and rail technology in most cases has a considerably lower minimum cost on a per unit PC basis.

Interestingly, the Fully Separated Elevated RoW and Fully Separated Underground facilities (RoW A) may well cost more to construct for both bus and rail on a per kilometre basis as shown on Figure 2, but when compared in terms of PC as in Figure 3, the picture changes. The right side of Figure 2 shows that if one invests in underground or elevated infrastructure, one should use it for high capacity transport units, as offered by rail borne vehicles.

\subsection{O\&M cost, passenger traffic density and expansion considerations}

In choosing a PT technology, the O\&M costs should be considered in addition to the capital costs. Figure 4 shows estimated O\&M costs per Network Route Kilometre (NRK) versus Passenger Traffic Density (PTD), which is defined as passenger-km per year per NRK. This means that both axes are normalized to the same unit to compare the O\&M costs for a given level of demand.

When comparing Semirapid Bus to Semirapid Rail, it is apparent that bus is less expensive below a PTD of 1 million and possibly still competitive at a PTD of 3 million. Above 3 million PTD, Semirapid Rail systems effectively blend into Rapid Rail. The data for Regional Rail, from North American systems, fall into two broad groups. First are the systems below 2 million PTD, which generally share tracks with a for-profit freight railway, paying trackage rights rather than having full responsibility for the infrastructure, which results in lower O\&M. Second are the systems with PTD higher than 2 million, which generally own the tracks, or at least maintain them, and are therefore bearing more of the full O\&M costs of a higher speed and capacity system.

The economies of scale in the O\&M costs of PT are clearly visible in Figure 4 . The data suggest that rail technology offers considerable potential for economies of scale, such that a rail system optimally sized to accommodate twice a given design volume may only cost as little as $62 \%$ more to operate when it is finally built out. In effect, the sizable fixed infrastructure investment is spread over more users as demand builds, and longer trains can deliver passenger $\times$ kilometres more cost-effectively.

However, as noted above, this does not mean that a small-scale rail project will cost less to operate than a small bus-based system. Bus-based systems do not require maintenance of tracks or OCS (except for trolley buses); however, for a doubling of capacity the O\&M costs for a bus-based system may increase by $90 \%$ or more. Considering future capacity expansions, rail technology's higher economies of scale could be an advantage to consider. 


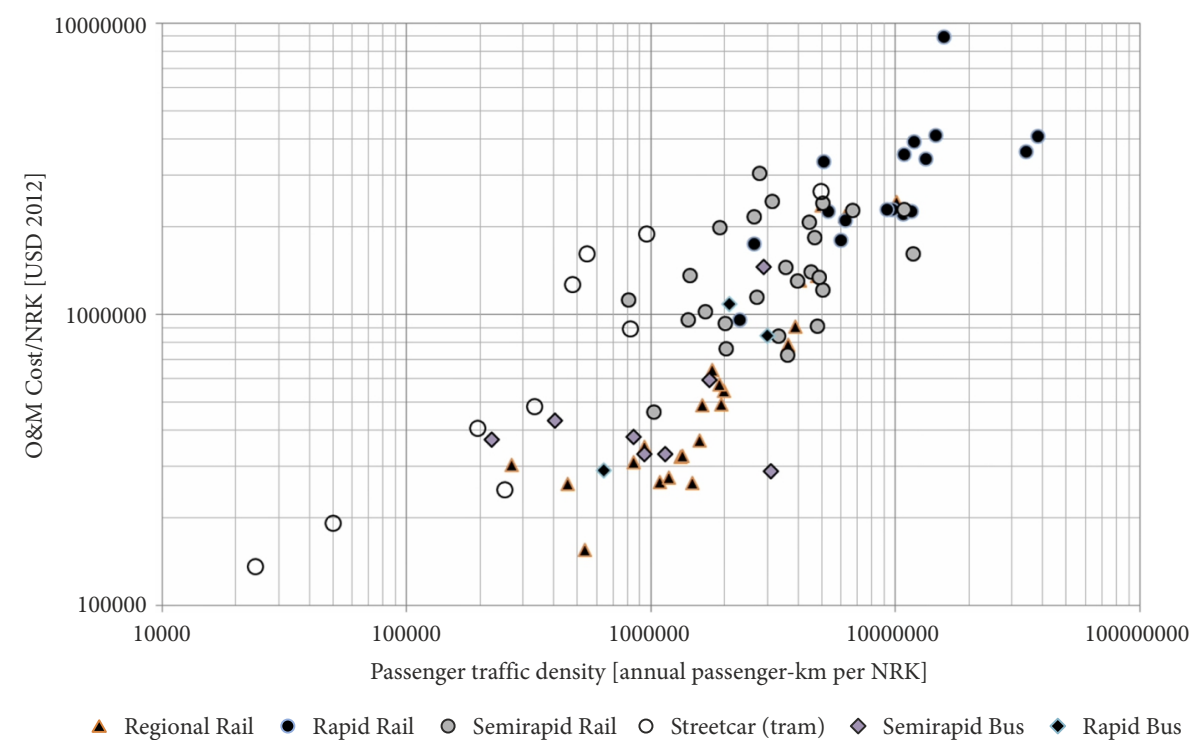

Figure 4. O\&M cost per NRK as a function of traffic density

Further economies of scale can manifest themselves by the conversion to trunk-feeder systems, and hub-andspoke (or pulse) multi-modal networks that eliminate a lot of duplicative capacity by using fewer but much higher capacity vehicles, enabled by the high PTD along the trunk. Thus, the same or higher level-of-service to O-D pairs on the feeder branches might well be possible for the same or lower operating budget, albeit with more transfers required (Bruun 2013). This has been confirmed in practice after the opening of some reconfigured networks using Semirapid Rail trunk lines (Thompson, Matoff 2003).

\subsection{Vehicle cost, speed and effective stop spacings}

The discussion so far has not included the contribution of vehicles to capital cost. The inclusion of these costs in persons $\times \mathrm{km}$ comparisons can obscure differences between systems because the number of vehicles per route $\mathrm{km}$ is dependent on both PTD (the demand) and the AOS. These two factors determine the number of transport units required per route-kilometre. Figure 5 shows vehicle cost expressed as a Net Present Value at different levels of demand using representative 2012 values for vehicle purchases in North America (e.g. $\$ 850000$ for an $18 \mathrm{~m}$ articulated bus and $\$ 3$ million for an articulated Light Rail Vehicle, based on authors' judgment). It assumes a lifecycle of 75 years and a discount rate of $5 \%$ with spaces computed as seats plus 4 persons per square meter in the standing areas, the loading typically cited for service planning in North America and Europe. The reason for the long timeframe is to capture the effects of the difference in vehicle service lifetimes. For rail vehicles, the US FTA suggests a 25 -year life, and for heavy-duty buses, 12 years. A minimum of 15 years for buses is more realistic. The values in Figure 5 presume three (3) sets of rail vehicles acquired over the project lifetime versus approximately five (5) sets of buses. The costs are computed per $\mathrm{km}$ of route.
As expected, there is a huge difference in cost as demand level increases from 5000 to 30000 passengers per hour (Figure 5). Overall and consistently across all levels of demand the annualized purchasing cost of the bus fleet is lower than that of a rail vehicle fleet. Of interest to designers of new PT systems and potential investments to upgrade performance is the effect of AOS as it can be more significant than the choice of vehicle technology.

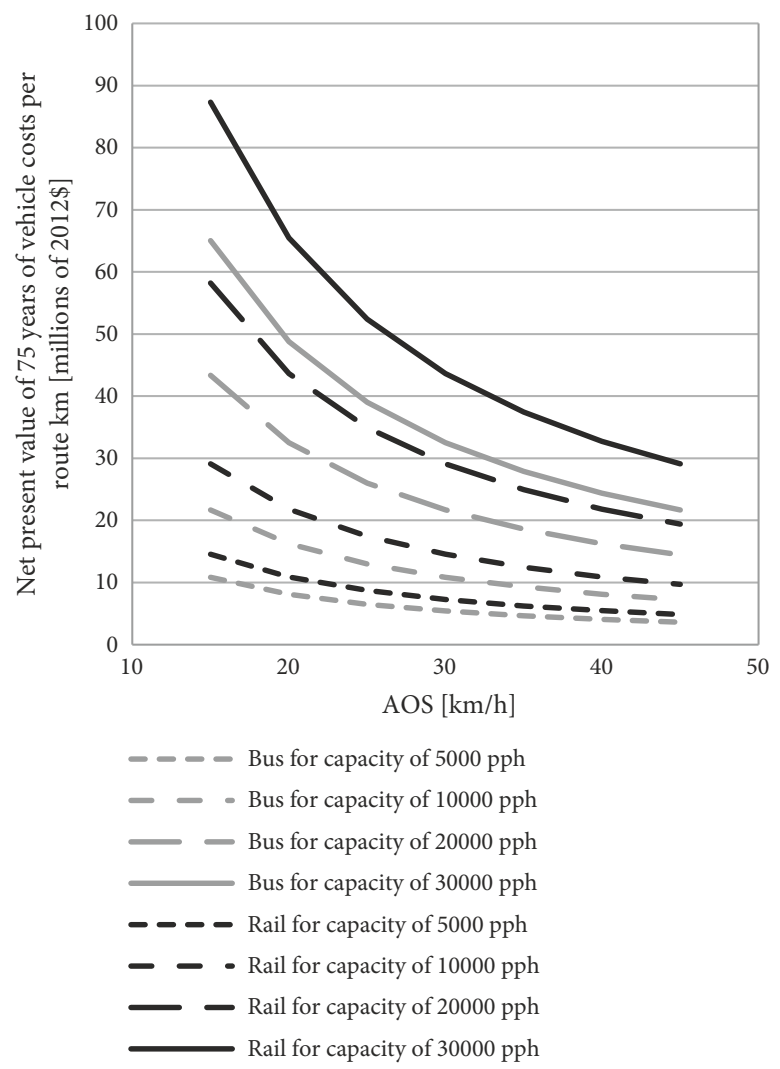

Figure 5. Lifecycle vehicle ownership cost as a function of AOS by technology and capacity 
Higher speed can dramatically reduce fleet size requirement at any given level of demand for both rail and bus technology; these capital savings, as well as the reductions in operating costs, can already make an investment in exclusive RoW or infrastructure worthwhile. The increase in speed attracts more passengers than any existing slower service in the same location, so more revenue will be collected as well.

The concept of "effective stop spacing" is now introduced to enable comparisons between different modal solutions that would connect the same set of stops or stations. If operating on the street, there would likely be some traffic-signal-controlled intersections that must be passed. The effective stop spacing is formed by considering each traffic signal on the route as the equivalent of 0.4 stops or stations.

Figure 6 shows the AOS versus the effective stop spacing (the horizontal axis). It shows the critical importance of the effective distance between stops to the range of AOS that might be attained with a clear trend upwards. Naturally, at any given effective spacing a mode that ran on fully grade-separated RoW A would have a much higher AOS than one that ran at-grade on ROW C. The range of speeds at effective station spacings below $0.5 \mathrm{~km}$, applicable to most Local Buses and Local Rail, is very wide, indicative of a wide range of congestion levels, vehicle door capacities, fare collection practices, and so on. It continues to be wide up to $1.5 \mathrm{~km}$ for both rail and bus technology, with the range in speed increasingly a function of whether segments of RoW A or RoW B, or transit priority features are employed.

Vehicle technology, as can be seen, really does not make that much of a difference for the AOS. The potentially higher acceleration and deceleration rates from electric propulsion cannot be fully exploited because of ride comfort criteria and the safety of standing passengers, at least at shorter station spacings. For effective stop spacings beyond $1.5 \mathrm{~km}$, there is a divergence where most Rapid

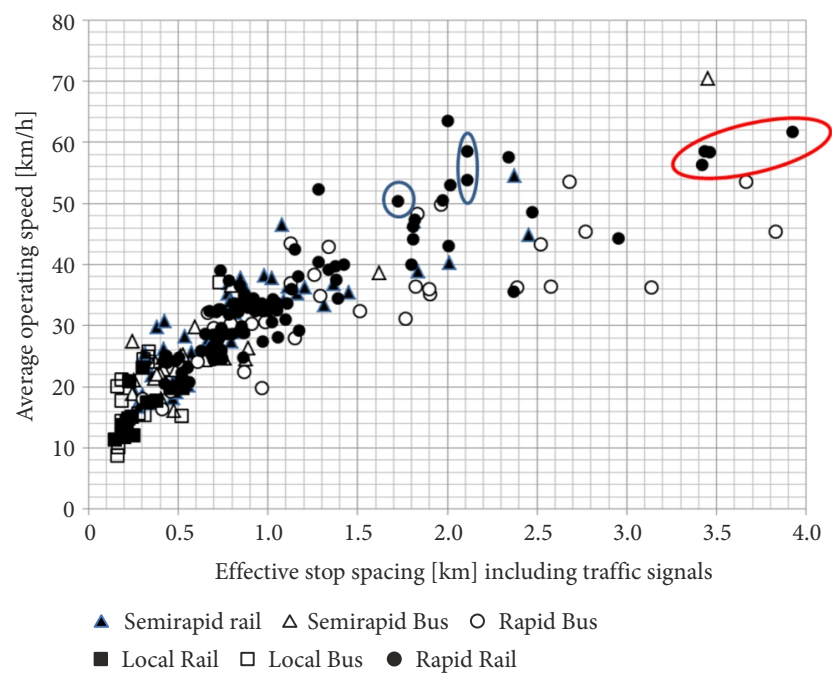

Figure 6. AOS as a function of station spacing for Bus and Rail Modes
Bus and Semirapid Rail services are slower than most Rapid Rail. This is due to the increasing use of RoW A, where Rapid Rail vehicles with higher performance capabilities can operate at higher cruising speeds than what safety regulations would allow for a manually steered vehicle.

The three (two plus one) circled points in Figure 6 near an effective stop spacing of $2.0 \mathrm{~km}$ represent three different lines of the Metropolitan Atlanta Regional Transit Authority (MARTA) Rapid Rail network. Similarly the four circled points near 3.5 to $4.0 \mathrm{~km}$ represents four branches on the Bay Area Rapid Transit (BART) system. MARTA and BART are both examples of Rapid/Regional Hybrid systems from Table 3, with relatively close station spacings in central parts of the region and longer station spacing in others.

\subsection{The passenger experience}

The third component in Table 3, the passenger experience, usually gets less attention in the early stages of the design characteristics of a PT system compared to the other two components. Perhaps this is because in relative terms it is the least costly, and in part, because it is derived from the decision on the other components. Yet it could have a large effect on the success of any PT system. The choice of technology (e.g. rail vs. bus) does not necessarily play a big role here although a preference for rail by passengers is usually assumed to exist by planners and elected officials even if problematic to confirm in practice (Mulley et al. 2014; Dell'Olio et al. 2012).

Convenience and comfort are somewhat subjective to define, but generally become more important as incomes rise. Important attributes include waiting times (as related to service headways) and the waiting conditions (as related to security and weather conditions), reliability of travel time, crowding (and seating vs. standing availability) and the ease of access to and egress from the service including the ease of transfers and the conditions to use time while travelling (e.g. using $\mathrm{Wi}-\mathrm{Fi}$ ). There is a tension in this respect between having short (distance) access and short end-to-end travel times on the PT service (Givoni, Rietveld 2007; Brons et al. 2009). The former argues for short station or stop spacings, the latter for longer station spacings, as was shown in Figure 6.

People with lower incomes are generally more willing to accept lower comfort standards (Batarce et al. 2015), such as crowding, than more affluent customers. The need to limit net O\&M costs (and hence subsidies) may even require such measures. By contrast, if the service must succeed at attracting riders with higher disposable incomes very high crowding conditions should be avoided in the peaks. Having said that, in London, Hong Kong, Tokyo or New York City passengers, as examples of highincome PT users (on average), crowding can still be very high because car driving conditions are quite congested and all-day parking is very expensive (Colliers International 2009). 
Overall, to a first approximation during initial design, setting the crowding standard is very important. The costs of providing other amenities are small details compared to providing sufficient capacity, but this does not mean they are of no importance. When resources are limited (and they always are) the value-for-money of investing in the passenger experience component could be much larger than investing further in the other components.

\subsection{Implementability}

Space precludes a detailed discussion of each item in Table 4 . Of these, the time frame is of particular relevance when the focus is on sustainability. If a region has a particularly serious emissions problem, for example, and quick effects are needed, then the delays in completion can mean urgent environmental benefits are deferred.

In principle, one of the advantages of solutions using RoW B (vs. RoW A) is the shorter construction period involved. However, the NIMBY phenomenon can lead to both public and political opposition to a certain PT system and certain components of it, while pressure from commercial stakeholders (through campaign and lobbying efforts) can lead to both political and public support for a certain PT system. In Delhi, India there were long delays to build the first Semirapid Bus line. Then after opening it was challenged in the courts by disgruntled auto owners. The right to convert the lanes was upheld, but the first line was still ultimately shut down in the end due to design and operational deficiencies. The entire multicorridor Semirapid Bus effort is starting anew. Meanwhile, another city in India, Ahmedabad, during the same time period has had good success in building several similar lines (PagetSeekins, Muñoz 2015).

As for projects involving RoW A, the conflict over use of surface space may be less, but the source of delay is instead likely to be geotechnical and can be equally detrimental to schedules (Flyvbjerg 2007).

The potential time delay is, in fact, merely one of the most important considerations in the larger category of risk assessment. Risk of failing to perform as planned can be minimized by using proven commercially available rolling stock and support equipment/facilities and conventional civil works designs. Demand risk can be mitigated with scalability features that allow for cost-effective adjustments.

Implementation issues can prove to be critical. Any cost-benefit evaluation must take into account the actual dates at which various alternatives are actually likely to be completed as well as the risks of cost overrun and underperformance. Using ex-post information about genuine peers one can establish a probability distribution for the cost-benefit ratio for each project solution alternative (Salling, Leleur 2011).

\section{Choosing the "fit for purpose" PT solution}

This paper makes several quantitative comparisons among various PT systems already in operation, using both bus and rail technology, but without regard to popular names or conceptions of a particular mode of transport. The paper focuses instead on components and design aspects that are relevant to get the performance necessary for the functional role of a PT system. Some generalizations of the results are possible.

Infrastructure investment costs increase as one moves from the least involved effort, minimum roadway work, to the most involved, a fully underground separated RoW. Rail examples always have the highest maximum cost, but there is substantial overlap in the bus and rail cost ranges. When viewed on a per unit of PC basis, rail still costs far more than bus when it is being installed with minimum roadway work, typical of Local Rail running on RoW C. For the remaining investments cases, rail is generally less costly, although the range can be very wide.

As the level of demand being served rises, as measured by PTD, the O\&M costs and costs per NRK, also rise but less than proportionally (estimated at 0.7 power of traffic density), indicative of the economies of scale enabled by the use of larger vehicles. Overall, probably the most central element that defines the nature of a PT system is not the vehicle technology, e.g. bus or rail, and not even, whether the infrastructure is rail or road based, but the characteristics of the alignment, particularly of the RoW.

The lifecycle capital costs for bus technology systems are lower than for rail at any level of PTD, but the difference reduces along with PTD, indicating a high acquisition cost for high performance rail vehicles. However, the effect from vehicle technology is far less than the effect of AOS. The reduced fleet size enabled by increased speed is far more important than the initial purchase and replacement purchase prices, regardless of modal technology. In turn, the effective stop spacing is the main determinant of AOS, not the modal technology. To enable decent speed performance between stations, lateral separation, RoW B, combined with traffic signal priority to enable crossing of intersections with minimum delay are needed, regardless of vehicle technology.

A central finding of this paper is that "rules of thumb", aggregate modal unit cost, or anecdotal data from other urban areas are not a sufficient ground for choosing between PT modes as generally understood. The right choice requires local knowledge of the nature of the specific travel markets, the combined PTD of all modes in the same corridor, street traffic conditions, the terrain and geotechnical conditions, the availability or cost of acquiring laterally separated or exclusive RoW, skilled construction labour costs, and materials costs.

From a financial standpoint, the choice also requires a careful balancing of initial capital costs and ongoing O\&M costs. The lower operating costs that come with a higher AOS are generally enabled by separated RoW. If the RoW is already available, the initial capital costs are reduced and the breakeven time for the lower O\&M costs to recover the initial investment is also reduced. The case for high initial capital investment is weakened where operating labour costs are lower, as in developing countries. 
With the continuing emergence of vehicle and technology variants that stretch established modal definitions, the concept of a mode of transport is morphing into a spectrum of possibilities. There is a need to untangle the performance requirements from the candidate technologies being considered. In the end, a package of technologies and civil engineering works should reflect the performance specifications that need to be met, especially capacity and AOS appropriate to the travel market. Furthermore, the "technical" solution space for choosing the attributes of the PT system must also respect various implementation constraints; some might be political in nature. Moving away from the counterproductive debate on BRT versus LRT or bus versus rail is important to advance PT in general. In order to improve value-for-money of PT it is instead critical to develop innovative component technologies and construction techniques, which are not necessarily rail or bus specific.

\section{References}

Batarce, M.; Muñoz J. C.; Ortúzar, J. de D.; Raveau, S.; Mojica, C.; Ríos, R. A. 2015. Evaluation of Passenger Comfort in Bus Rapid Transit Systems. Technical Note No. IDB-TN-770. InterAmerican Development Bank, Infrastructure and Environment Sector, Transport Division. Washington, DC, US. 67 p.

Brons, M.; Givoni, M.; Rietveld, P. 2009. Access to railway stations and its potential in increasing rail use, Transportation Research Part A: Policy and Practice 43(2): 136-149. https://doi.org/10.1016/j.tra.2008.08.002

Bruun, E. C. 2013. Better Public Transit Systems: Analyzing Investments and Performance. Chapter 3: Route and Network Analysis. Routledge, UK, 57-105.

CEREMA. 2014. Transports collectifs urbains (TCU): évolution 2007-2012. Centre d'études et d'expertise sur les risques, l'environnement, la mobilité et l'aménagement (CEREMA). 521 p. (in French).

Colliers International. 2009. Parking Rates: Global CBD Parking Rate Survey 2009. Available from Internet:

http://www.colliers.com

Currie, G.; Delbosc, A. 2013. Exploring comparative ridership drivers of bus rapid transit and light rail transit routes, Journal of Public Transportation 16(2): 47-65.

http://doi.org/10.5038/2375-0901.16.2.3

Currie, G.; Delbosc, A.; 2014. Assessing bus rapid transit system performance in Australasia, Research in Transportation Economics 48: 142-151.

https://doi.org/10.1016/j.retrec.2014.09.012

CUTA. 2013. Canadian Transit Fact Book: 2012 Operating Data. Canadian Urban Transit Association (CUTA). Available from Internet: http://cutaactu.ca

De Oña, J.; De Oña, R.; Eboli, L.; Mazzulla, G. 2016. Index numbers for monitoring transit service quality, Transportation Research Part A: Policy and Practice 84: 18-30. https://doi.org/10.1016/j.tra.2015.05.018

Dell'Olio, L.; Ibeas, Á.; Cecín, P. 2011. The quality of service desired by public transport users, Transport Policy 18(1): 217227. https://doi.org/10.1016/j.tranpol.2010.08.005

Dell'Olio, L., Ibeas, Á.; Cecín, P. 2010. Modelling user perception of bus transit quality, Transport Policy 17(6): 388-397.

https://doi.org/10.1016/j.tranpol.2010.04.006
Dell'Olio, L.; Ibeas, A.; Dominguez, A.; Gonzalez, F. 2012. Passenger preference analysis: light rail transit or bus versus car, Transport 27(3): 276-285.

https://doi.org/10.3846/16484142.2012.719839

Finn, B.; Heddebaut, O.; Kerkhof, A.; Rambaud, F.; Lozano, O. S.; Soulas, C. 2011. Bus à Haut Niveau de Service: Caractéristiques fondamentales et recommandations pour la prise de décision et la recherché. Rapport final: COST TU0603. Coopération européenne dans le domaine de la recherche scientifique et technique [European Cooperation in Science and Technology]. 226 p. (in French).

Flyvbjerg, B. 2007. Policy and planning for large-infrastructure projects: problems, causes, cures, Environment and Planning B: Urban Analytics and City Science 34(4): 578-597. https://doi.org/10.1068/b32111

FTA. 2013. The National Transit Database (NTD). US Federal Transit Administration (FTA), US Department of Transportation, Washington, DC, US. Available from Internet: https:// www.transit.dot.gov/ntd

Givoni, M.; Rietveld, P. 2007. The access journey to the railway station and its role in passengers' satisfaction with rail travel, Transport Policy 14(5): 357-365.

https://doi.org/10.1016/j.tranpol.2007.04.004

Hensher, D. A. 2016. Why is light rail starting to dominate bus rapid transit yet again?, Transport Reviews 36(3): 289-292. https://doi.org/10.1080/01441647.2016.1155851

Hensher, D. A.; Mulley, C. 2015. Modal image: candidate drivers of preference differences for BRT and LRT, Transportation 42(1): 7-23. https://doi.org/10.1007/s11116-014-9516-7

Hensher, D. A.; Stanley, J. 2003. Performance-based quality contracts in bus service provision, Transportation Research Part A: Policy and Practice 37(6): 519-538.

https://doi.org/10.1016/S0965-8564(03)00006-5

Hensher, D. A.; Stopher, P.; Bullock, P. 2003. Service quality developing a service quality index in the provision of commercial bus contracts, Transportation Research Part A: Policy and Practice 37(6): 499-517.

https://doi.org/10.1016/S0965-8564(02)00075-7

Jarzab, J.; Lightbody, J.; Maeda, E. 2002. Characteristics of bus rapid transit projects: an overview, Journal of Public Transportation 5(2): 31-46. http://doi.org/10.5038/2375-0901.5.2.2

Mulley, C.; Hensher, D. A.; Rose, J. 2014. Do preferences for BRT and LRT vary across geographical jurisdictions? A comparative assessment of six Australian capital cities, Case Studies on Transport Policy 2(1): 1-9.

https://doi.org/10.1016/j.cstp.2013.11.001

Ney, S. 2009. Resolving Messy Policy Problems: Handling Conflict in Environmental, Transport, Health and Ageing Policy. Routledge. $224 \mathrm{p}$.

Paget-Seekins, L.; Muñoz, J. C. 2015. Contested space for mobility: conflicts over busway projects in developing cities, in TRB 94th Annual Meeting Compendium of Papers, 11-15 January 2015, Washington, DC, US, 1-16.

Rittel, H. W. J., Webber, M. M. 1973. Dilemmas in a general theory of planning, Policy Sciences 4(2): 155-169. https://doi.org/10.1007/BF01405730

Salling, K. B.; Leleur, S. 2011. Transport appraisal and Monte Carlo simulation by use of the CBA-DK model. Transport Policy 18(1): 236-245. https://doi.org/10.1016/j.tranpol.2010.08.007

Stutsman, J. 2002. Bus rapid transit or light rail transit - how to decide?: Los Angeles case study, Transportation Research Record: Journal of the Transportation Research Board 1793: 55-61. https://doi.org/10.3141/1793-08 
Thompson, G. L.; Matoff, T. G. 2003. Keeping up with the joneses: radial vs. multidestinational transit in decentralizing Regions, Journal of the American Planning Association 69(3): 296-312. https://doi.org/10.1080/01944360308978021

TRB. 2003. Transit Capacity and Quality of Service: Manual. Transit Cooperative Research Program (TCRP) Report 100. Transportation Research Board (TRB), Washington, DC, US.
Vuchic, V. R. 2007. Urban Transit Systems and Technology. Chapter 4: Transit system performance: capacity, productivity, efficiency, and utilization. Wiley, Canada. 149-201. https://doi.org/10.1002/9780470168066.ch4

\section{APPENDIX}

\section{Capital cost and PC components of public transport in different settings}

\begin{tabular}{|c|c|c|c|c|c|c|c|c|c|c|c|c|c|c|}
\hline \multirow[b]{2}{*}{$\begin{array}{l}\text { Cost [millions } \\
\$ 2012]\end{array}$} & \multicolumn{2}{|c|}{$\begin{array}{l}\text { Minimal } \\
\text { roadway } \\
\text { work }\end{array}$} & \multicolumn{2}{|c|}{$\begin{array}{c}\text { Dedicated } \\
\text { arterial } \\
\text { running way }\end{array}$} & \multicolumn{2}{|c|}{$\begin{array}{c}\text { At grade } \\
\text { in available } \\
\text { ERW }^{*}\end{array}$} & \multicolumn{2}{|c|}{$\begin{array}{c}\text { At grade } \\
\text { in new ERW }\end{array}$} & \multicolumn{2}{|c|}{$\begin{array}{l}\text { At grade rapid } \\
\text { way }\end{array}$} & \multicolumn{2}{|c|}{$\begin{array}{l}\text { Elevated rapid } \\
\text { way }\end{array}$} & \multicolumn{2}{|c|}{$\begin{array}{l}\text { Underground } \\
\text { rapid way }\end{array}$} \\
\hline & Low & High & Low & High & Low & High & Low & High & Low & High & Low & High & Low & High \\
\hline $\begin{array}{l}\text { Running way } \\
\text { infrastructure }\end{array}$ & $\$ 0.3$ & $\$ 0.7$ & $\$ 10.0$ & $\$ 15.0$ & $\$ 10.0$ & $\$ 15.0$ & $\$ 20.0$ & $\$ 30.0$ & $\$ 25.0$ & $\$ 35.0$ & $\$ 50.0$ & $\$ 75.0$ & $\$ 80.0$ & $\$ 120.0$ \\
\hline $\begin{array}{l}\text { Rail technology } \\
\text { running way } \\
\text { premium }\end{array}$ & $\$ 8.5$ & $\$ 10.0$ & $\$ 8.0$ & $\$ 10.0$ & $\$ 8.5$ & $\$ 12.0$ & $\$ 10.0$ & $\$ 12.0$ & $\$ 10.0$ & $\$ 12.0$ & $\$ 12.0$ & $\$ 15.0$ & $\$ 12.0$ & $\$ 15.0$ \\
\hline $\begin{array}{l}\text { Stations } \\
(500 \ldots 1500 \mathrm{~m})\end{array}$ & $\$ 0.0$ & $\$ 0.1$ & $\$ 0.1$ & $\$ 0.3$ & $\$ 0.3$ & $\$ 4.3$ & $\$ 0.3$ & $\$ 4.3$ & $\$ 4.5$ & $\$ 20.0$ & $\$ 6.0$ & $\$ 30.0$ & $\$ 15.0$ & $\$ 85.0$ \\
\hline $\begin{array}{l}\text { Rail station } \\
\text { premium }\end{array}$ & $\$ 0.0$ & $\$ 0.1$ & $\$ 0.1$ & $\$ 0.1$ & $\$ 0.4$ & $\$ 2.0$ & $\$ 0.4$ & $\$ 2.0$ & $\$ 3.3$ & $\$ 12.0$ & $\$ 3.5$ & $\$ 13.4$ & $\$ 16.0$ & $\$ 47.9$ \\
\hline Real estate & $\$ 0.0$ & $\$ 0.0$ & $\$ 0.3$ & $\$ 3.0$ & $\$ 0.3$ & $\$ 8.0$ & $\$ 0.5$ & $\$ 20.0$ & $\$ 0.5$ & $\$ 20.0$ & $\$ 0.5$ & $\$ 20.0$ & $\$ 0.5$ & $\$ 30.0$ \\
\hline $\begin{array}{l}\text { Station parking } \\
\text { (local) }\end{array}$ & $\$ 0.0$ & $\$ 0.0$ & $\$ 0.0$ & $\$ 1.0$ & $\$ 0.0$ & $\$ 3.0$ & $\$ 0.0$ & $\$ 6.0$ & $\$ 0.0$ & $\$ 6.0$ & $\$ 0.0$ & $\$ 6.0$ & $\$ 0.0$ & $\$ 6.0$ \\
\hline $\begin{array}{l}\text { Rail station } \\
\text { parking } \\
\text { premium }\end{array}$ & $\$ 0.0$ & $\$ 0.0$ & $\$ 0.0$ & $\$ 0.5$ & $\$ 0.0$ & $\$ 1.0$ & $\$ 0.0$ & $\$ 2.0$ & $\$ 0.0$ & $\$ 2.0$ & $\$ 0.0$ & $\$ 2.0$ & $\$ 0.0$ & $\$ 2.0$ \\
\hline $\begin{array}{l}\text { Streetscape } \\
\text { improvements }\end{array}$ & $\$ 0.0$ & $\$ 5.0$ & $\$ 1.0$ & $\$ 20.0$ & $\$ 0.0$ & $\$ 2.0$ & $\$ 0.0$ & $\$ 5.0$ & $\$ 0.0$ & $\$ 5.0$ & $\$ 0.0$ & $\$ 5.0$ & $\$ 0.0$ & $\$ 5.0$ \\
\hline $\begin{array}{l}\text { Adjunct } \\
\text { improvements }\end{array}$ & $\$ 0.0$ & $\$ 0.0$ & $\$ 0.0$ & $\$ 0.0$ & $\$ 0.0$ & $\$ 2.0$ & $\$ 0.0$ & $\$ 10.0$ & $\$ 0.0$ & $\$ 15.0$ & $\$ 0.0$ & $\$ 10.0$ & $\$ 0.0$ & $\$ 10.0$ \\
\hline Bus total & $\$ 0.3$ & $\$ 5.8$ & $\$ 11.4$ & $\$ 39.3$ & $\$ 10.6$ & $\$ 34.3$ & $\$ 20.8$ & $\$ 75.3$ & $\$ 30.0$ & $\$ 101.0$ & $\$ 56.5$ & $\$ 146.0$ & $\$ 95.5$ & $\$ 256.0$ \\
\hline Rail total & $\$ 8.8$ & $\$ 15.9$ & $\$ 19.5$ & $\$ 49.9$ & $\$ 19.5$ & $\$ 49.3$ & $\$ 31.2$ & $\$ 91.3$ & $\$ 43.3$ & $\$ 127.0$ & $\$ 72.0$ & $\$ 176.4$ & $\$ 123.5$ & $\$ 320.9$ \\
\hline $\begin{array}{l}\text { Productive } \\
\text { capacity }\end{array}$ & Low & High & Low & High & Low & High & Low & High & Low & High & Low & High & Low & High \\
\hline $\begin{array}{l}\text { Bus capacity } \\
\text { [persons per } \\
\text { hour] }\end{array}$ & 3500 & 7000 & 5500 & 9000 & 6000 & 11000 & 6000 & 11000 & 10000 & 22500 & 10000 & 22500 & 10000 & 22500 \\
\hline $\begin{array}{l}\text { Rail capacity } \\
\text { [persons per } \\
\text { hour] }\end{array}$ & 4500 & 10000 & 11000 & 14000 & 14000 & 19000 & 14000 & 19000 & 15000 & 55000 & 15000 & 55000 & 15000 & 55000 \\
\hline $\begin{array}{l}\text { Bus operating } \\
\text { speed }[\mathrm{km} / \mathrm{h}]\end{array}$ & 10 & 12 & 12 & 18 & 15 & 23 & 15 & 25 & 25 & 35 & 25 & 35 & 25 & 35 \\
\hline $\begin{array}{l}\text { Rail operating } \\
\text { speed }[\mathrm{km} / \mathrm{h}]\end{array}$ & 10 & 12 & 12 & 18 & 18 & 30 & 18 & 30 & 25 & 35 & 25 & 35 & 25 & 35 \\
\hline $\begin{array}{l}\text { Bus productive } \\
\text { capacity }\end{array}$ & 35000 & 84000 & 66000 & 162000 & 90000 & 253000 & 90000 & 275000 & 250000 & 787500 & 250000 & 787500 & 250000 & 787500 \\
\hline $\begin{array}{l}\text { Rail productive } \\
\text { capacity }\end{array}$ & 45000 & 120000 & 132000 & 252000 & 252000 & 570000 & 252000 & 570000 & 375000 & 1925000 & 375000 & 1925000 & 375000 & 1925000 \\
\hline $\begin{array}{l}\text { Cost per unit } \\
\text { productive } \\
\text { capacity }\end{array}$ & \multicolumn{2}{|c|}{ Range } & \multicolumn{2}{|c|}{ Range } & \multicolumn{2}{|c|}{ Range } & \multicolumn{2}{|c|}{ Range } & \multicolumn{2}{|c|}{ Range } & \multicolumn{2}{|c|}{ Range } & \multicolumn{2}{|c|}{ Range } \\
\hline Bus & $\$ 8.6$ & $\$ 69.0$ & $\$ 172.7$ & $\$ 242.6$ & $\$ 117.6$ & $\$ 135.5$ & $\$ 230.9$ & $\$ 273.7$ & $\$ 120.0$ & $\$ 128.3$ & $\$ 226.0$ & $\$ 185.4$ & $\$ 382.0$ & $\$ 325.1$ \\
\hline Rail & $\$ 195.6$ & $\$ 132.5$ & $\$ 147.7$ & $\$ 198.0$ & $\$ 77.2$ & $\$ 86.5$ & $\$ 123.7$ & $\$ 160.1$ & $\$ 115.5$ & $\$ 66.0$ & $\$ 192.0$ & $\$ 91.6$ & $\$ 329.3$ & $\$ 166.7$ \\
\hline
\end{tabular}

Note: ${ }^{*}$ ERW - Exclusive Right of Way (not shared by general vehicular traffic). 